\title{
PATCHY DISTRIBUTIONS OF ANT SPECIES IN NEW GUINEA RAIN FORESTS
}

\author{
By EDWARD O. WILSON \\ Biological Laboratories, Harvard University
}

While recently engaged in field work in New Guinea the author had several excellent opportunities to study local areal distribution of rain forest ants. During one threeweek period in April, 1955, a walk was made from Finschhafen, on the eastern tip of the Huon Peninsula, west for a distance of 45 kilometers through the midmountain rain forests of the Dedua-Hube regions to Tumnang and Laulaunung, thence south for thirty kilometers to Butala on the southern coast. In the vicinity of Lae intensive collecing was conducted over a distance of twelve kilometers in rccently continuous lowland rain forest within the triangle formed by Didiman Creek, Bubia, and the section between the Busu and Bupu Rivers.

Areal distributions of individual species were found to be almost universally patchy, despite the external appearance of uniformity of the rain forest environment. Furthermore, in the cases of species abundant enough to be studied in some detail, the patchiness seemed to obtain at two levels of distribution, which for purposes of description here will be referred to as "microgeographic" and "geographic".

Microgeographic patchiness. The species common enough to be studied in detail are also relatively adaptable, occurring usually in spots of variable canopy density (see below) and sometimes in more than one major forest type (e.g., Leptogenys dimunuta (Fr. Smith), which ranges from medium lowland rain forest to dry, monsoon forest). In this respect, at least, they seem to be no more specialized than the majority of temperate ant species. At the same time, they show definite preferences for certain local environmental con-

Explanation of Plate 3

Plate 3. Primary medium-aspect rain forest near the lower Busu River, Northeast New Guinea. A bulldozer trail cuts through the lower left hand corner of the picture. 


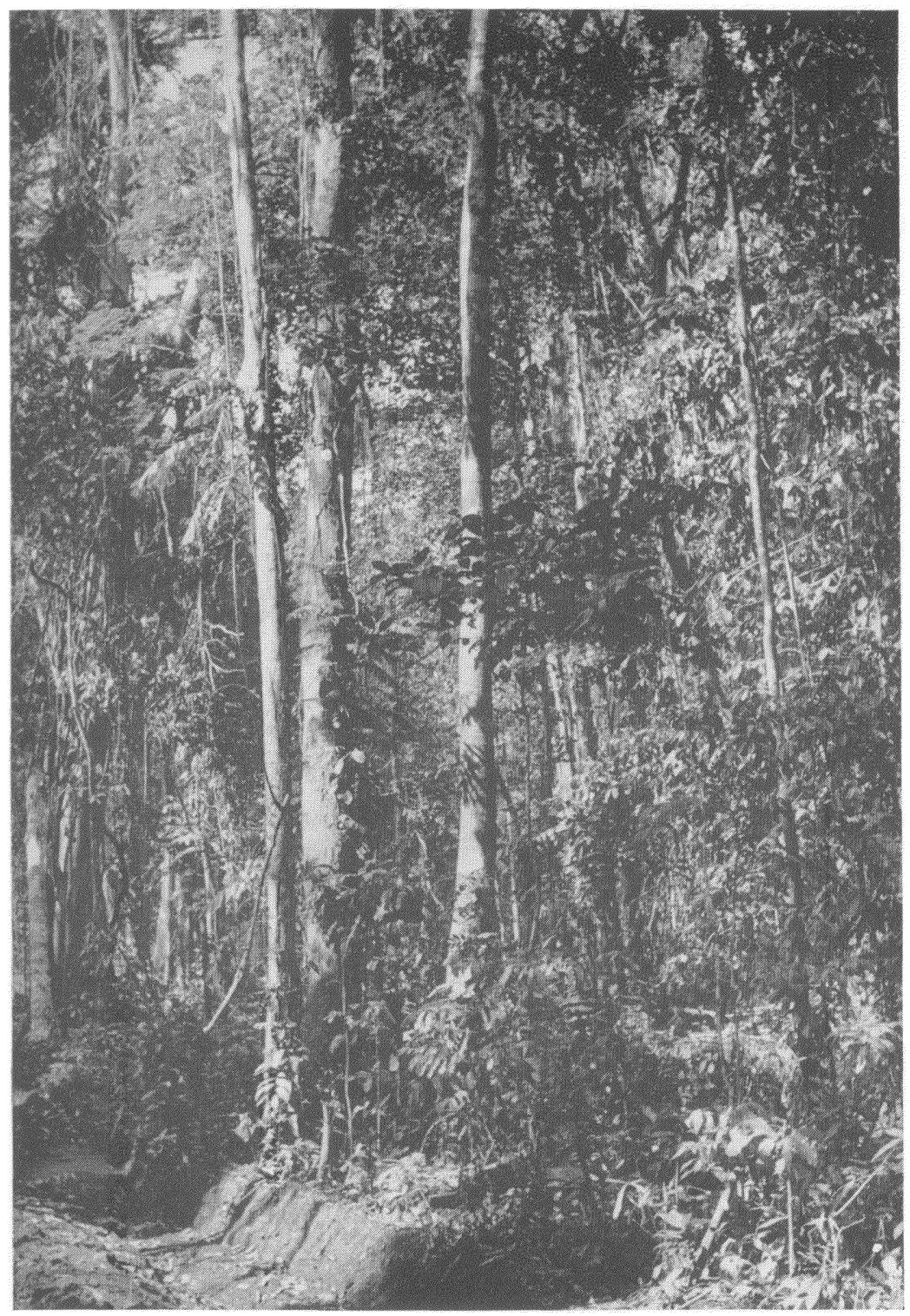

WiLson - Nhw Guinha Rain forlis't 
ditions. At the Busu River and in other lowland rain forest sites investigated, ant species tended to be segregated into local areas, sometimes a hectare in extent or less, which could be distinguished from adjacent areas by their specific canopy densities. When the total range of possible canopy densities at the Busu River, from the open aspect that fringes savanna areas, to the most closed aspect, ordinarily found covering sloughs, was arbitrarily divided into three divisions (open, medium, dense) and their faunas studied, the fo!lowing microgeographic segregation of ant species was noted.

"Open rain forest". (Plate 5) Broken canopy; considerable ground insolation; leaf litter 2 to $15 \mathrm{~cm}$. thick; leaf mold present but thin and relatively dry; soil loose, well aerated, and relatively dry; moss scarce on both ground and tree trunks; A-stratum trees generally less than thirty meters high; lianes and plank buttresses much less common than in other two divisions; recumbent vines common on ground; soil and rotting logs generally thoroughly penetrated with dense root and rhizome growth; undergrowth relatively dense; sufficient to make human progress across the forest floor difficult. This is the aspect of old secondgrowth forest and may be created naturally by the fall of large forest trees or, in mountainous areas, by rockslides. It is also a more or less permanent feature of the fringe of forest, genera!ly one to two hundred meters wide, that borders savanna areas. Occasional spots deep within rain forest approach the open aspect even though an immediate cause, such as a large fallen tree, is not in evidence. Ant species that appear to reach their maximum density in open rain forest at the Busu River included Platythyrea parallela (Fr. Smith), Diacamma rugosum (Le Guillou), Odontomachus simillimus (Fr. Smith), and Cardiocondyla paradoxa (Emery). In the canopy of the open forest, species of Crematogaster, especially subgenus Xiphocrema, and of Technomyrmex increased generally, while those of Iridomyrmex decreased.

"Medium rain forest". (Plates 3, 4). By far the largest lowland area in the Lae area is covered by forest of the following aspect: closed canopy; ground insolation slight; 
leaf litter as in open aspect; underlying leaf mold rich and moist; soil loose, well aerated and drained and relatively moist; moss common on the surface of the ground, on rotting wood lying on the ground and on tree trunks; A-stratum trees average 40 meters or more in height; plank buttresses common; lianes and epiphytes abundant; under growth sparse, making human progress across the forest floor easy. The majority of endemic ant species are concentrated in this division. Examples of genera that reached maximum density (in 1955) on the floor of the Busu forest included Ponera, Myopias, Ectomomyrmex, Pheidole, Strumigenys, Rhopalothrix, Myrmecina, and Pristomyrmex. In the canopy Iridomyrmex heavily predominated.

"Dense rain forest". Closed canopy; little or no ground insolation; leaf litter thin, with one-quarter or more of the ground surface completely bare; leaf mold very poorly developed; soil dense, less well drained and moister than in medium forest; parts of the ground surface occasionally holding shallow pools of water after heavy rains; moss abundant, especially on larger rotting logs; A-stratum trees as tall as in medium forest; plank buttresses common; lianes and epiphytes abundant; undergrowth very sparse, even more so than in medium forest. Ants reaching maximum density in various strata of this division at the Busu River included some species of Pheidologeton, Tetramorium, Leptomyrmex and Iridomyrmex.

Careful analysis would probably reveal many finer details of microgeographic segregation than those indicated here, for the rain forest is an extraordinarily complex mosaic of local habitats, exhibiting seemingly endless nuances and combinations of erosion states, growth and death of vegetation, composition of leaf mold, and other environmental features. Ant species did not appear to be limited to any of these particular divisions within the rain forest proper. At most, the divisions probably serve as density foci, from which the species are constantly pressing out into adjacent, less favorable habitats,

Geographic patchiness. Ant species apparently show extensive and unpredictable variation in population density over short geographic distances above and beyond that already 
noted with respect to microgeographic habitat segregation. This phenomenon was first observed in the Hube area of the Huon Peninsula, where, through a few kilometers distance in seemingly uniform mid-mountain forest, dominant species of the genera Aphaenogaster (Planimyrma), Meranoplus, and Leptomyrmex showed conspicuously irregular density patterns. The impression was gained that even within the most favored habitats these species showed irregular density patterns. This type of discontinuous distribution is superimposed on the mosaic, habitat-correlated microgeographic patchiness, and the two conditions probably grade into each other. It can be predicted that superimposition of the two levels of patchiness will result in very irregular and complex individual species distributions, which in turn will have a profound effect on the differentiation of local faunas at localities separated by as little as a few kilometers distance. Such an effect was in fact observed in the lowland rain forests of the Lae area, as described below

Differentiation of local faunas in the Lae area. In 1955 most of the area to the north of Lae and east of the nearby Busu River was covered with a mixture of primary and secondary rain forest, with occasional savanna enclaves. Native villages were not numerous, and native agriculture had not made serious inroads into the forest. In the vicinity of Bubia, to the northwest of Lae, extensive land was under cultivation, partly by the Government Agricultural Experiment Station, but even here the forest was still partly intact, and primary tracts were still accessible ${ }^{1}$.

1 According to both Mr. Henry G. Eckhoff and Mr. Carl M. Jacobson (pers. commun.), who were among the first European settlers of the Lae district, extensive clearing of the forests of this area is a comparatively recent event. Prior to 1925 the only European settlement was the mission station at Malahang, on the coast near Lae. In 1925 a small amount of ground was cleared at Didiman Creek to establish the Goverment Agricultural Experimental Station. Between 1925 and 1930, further clearing proceeded in the vicinity but was still restricted to the present town limits of Lae. Mr. Eckhoff, who arrived in 1928, states that in 1929-30, "My wife and I were the only residents of Lae other than the air freighting companies. There were no other agricultural activities". The next principal developmenl was the establishment of a poultry farm just outside the Lae township by Mr. Jacobson. During the Second World War a road was built from Lae through Bubia to the airfield at Nadzab. Since 1945 clearing for agricultural purposes has proceeded to a limited extent of either side of this road. 
Three localities within this forested area were chosen as sites of intensive collecting (see figure 1). The Busu-Bupu forest was the least disturbed of the three; lumbering operations had commenced in the collecting area only the year before, and most of the forest seemed in primary condition. The Didiman Creek site contained a tract of forest, at least partly second-growth in nature, that had been preserved within the Government Agricultural Experimental Station on the northern edge of Lae. At Bubia, extensive forest tracts, primary at least in part, extended to the east of the Jacobson Plantation. The forest tracts at these three localities represent relict segments of what can reasonably be assumed to have been continuous, predominantly primary lowland forest as recently as thirty years ago. Bubia and

TABLE I.

Bubia Didiman Cr. Busu R.

Cardiocondyla paradoxa Emery

Crematogaster (Acrocoelia)

$\mathrm{X}$ irritabilis (Fr. Smith)

Crematogaster (Rhachiocrema) sp. nov.

Tetramorium validiusculum $\mathrm{XXX}$ Emery

Tetramorium ornatum Emery - $\quad$ XX $\quad$ XX

Triglyphothrix fulviceps $\quad-\quad$ XX $\quad$ XX Emery

Aphaenogaster dromedarius $\quad-\quad$ - $\quad$ - $\quad \mathrm{XX}$ Emery

Meranoplus hirsutus (Fr. Smith) X - $\quad$ XX Leptomyrmex fragilis $\quad \mathrm{XX} \quad \mathrm{XX}$ (Fr. Smith)

Pseudo'asius breviceps Emery XXX $\quad$ XX $\quad$ X

Subjective estimates of relative abundance of some dominant ant species at three neighboring localities in New Gunea. A dashed line means absent, or at least never observed; a single $\mathrm{X}$, present but collected only once or twice; double-X moderately abundant; triple-X among the two or three most abundant species at the locality. Since collecting trips were wide-ranging, these estimates reflect most closely the relative abundance of colonies, rather than number of workers or biomass. Further explanation in text. 
Busu-Bupu regions were almost connected by continuous forest even as late as 1955 . There is no reason to believe

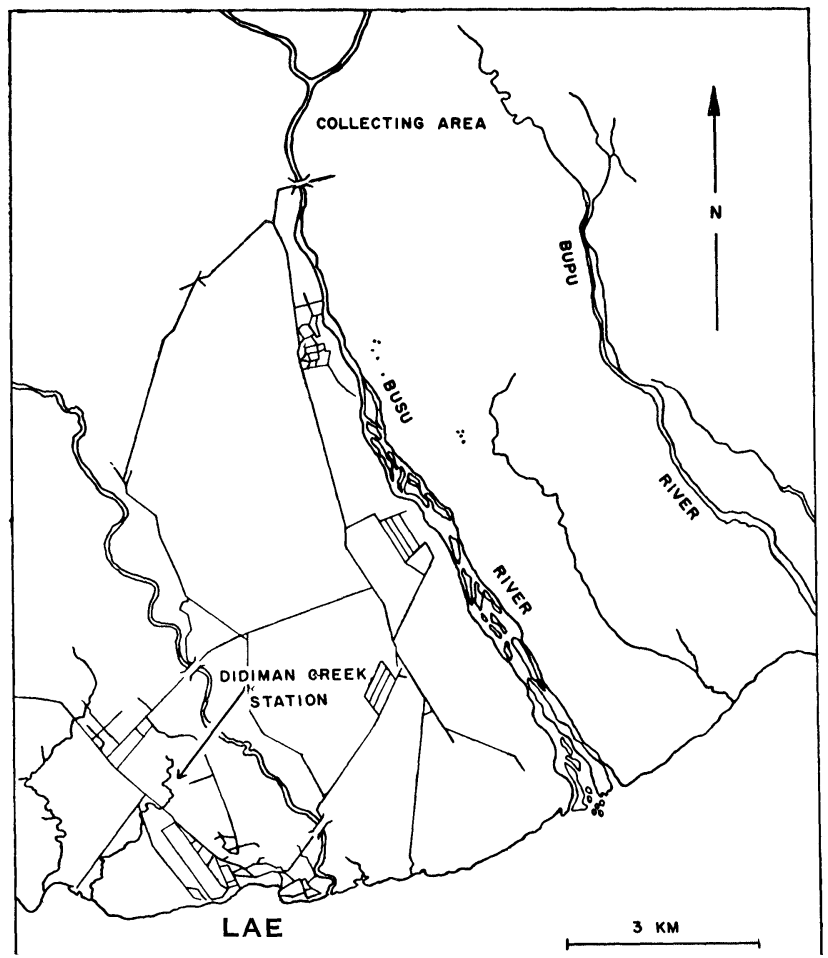

Figure 1. Map of the Lae area in 1955, showing Didiman Creek and the Busu-Bupu area, two of the collecting stations studied with respect to local distribution of species. The third station, Bubia, is located 12.5 kilometers to the northwest of the town of Lae.

\section{Explanation of Plate 4}

Plate 4. Floor of primary medium-aspect rain forest near lower Busu River. An overhead tree has just been felled to allow in an unusual amount of sunlight. The exposed portion of the machete is approximately 20 inches, or 50 centimeters, in length. The greatest concentration of species and individual colonies to be found anywhere in New Guinea nest in small pieces of rotting wood in this situation. 


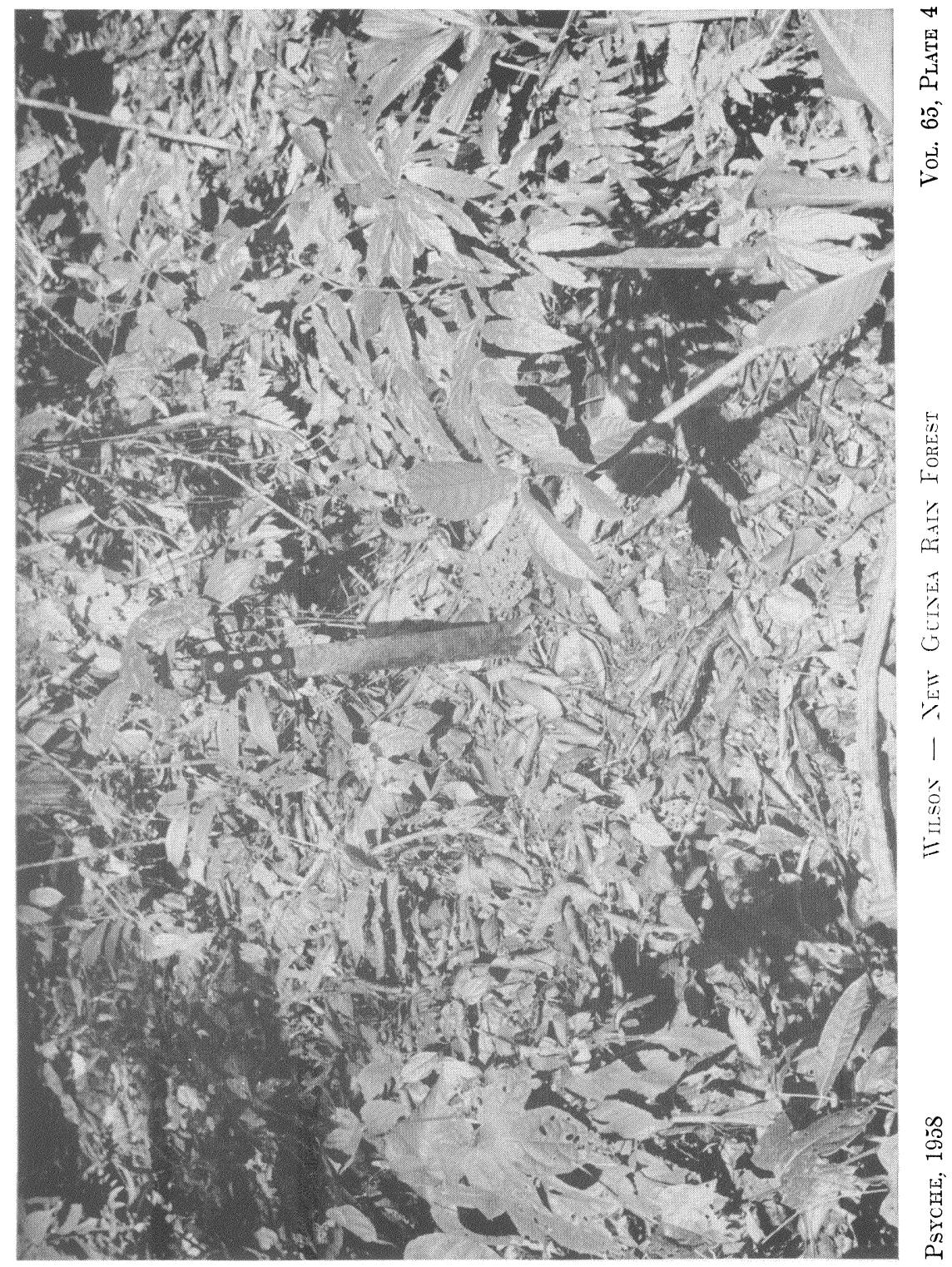


that the forests at the three localities, or the ant faunas in them, had been seriously disturbed by man. All three localities contained rich endemic Papuan faunas, with virtually no infi tration of introduced species.

Subjective impressions of the relative abundance of several of the dominant ant species are presented in Table 1. In each of the three localities, all of the major microgeographic areal divisions were studied. Each locality was visited at least twice during the author's two month stay in the Lae area, and a minimum of four days devoted to intensive collecting. Under these conditions, only the commonest species could be compared, but differences in local abundance of these were so striking that it seems safe to predict that similar patchy distributions are exhibited by other, less dominant members of the fauna.

\section{Discussion: The Evolutionary Implications oF PATChIness}

In any appraisal of comparative ecology, the New Guinea ant fauna is to be characterized first of all by the exceptional richness of its species and the great size of its biomass. The present study has shown that in addition to sheer size, an additional factor adds greatly to the total faunal complexity. This is the discordant patchy distribution of individual species. The fractioning of species into small subpopulations that are partially isolated from one another probably results in relatively high rates of evolution, whether through random drift or differential selective pressures or both (see for instance Kimura, 1955, and Ford, 1955). Moreover, as a result of discordant patchiness, no two localities harbor exactly the same fauna. Considering that several hundreds of species are thus involved, it is clear that the spatiotemporal structure of the entire New Guinea fauna must present the appearance of a great kaleidoscope. The effects of such a structure on the evolution of individual species of

Explanation of Plate 5

Plate 5. Floor of primary open-aspect rain forest near the lower Busu River. The undergrowth at this spot is made up preponderantly of an unidentified speces of Selaginella. 


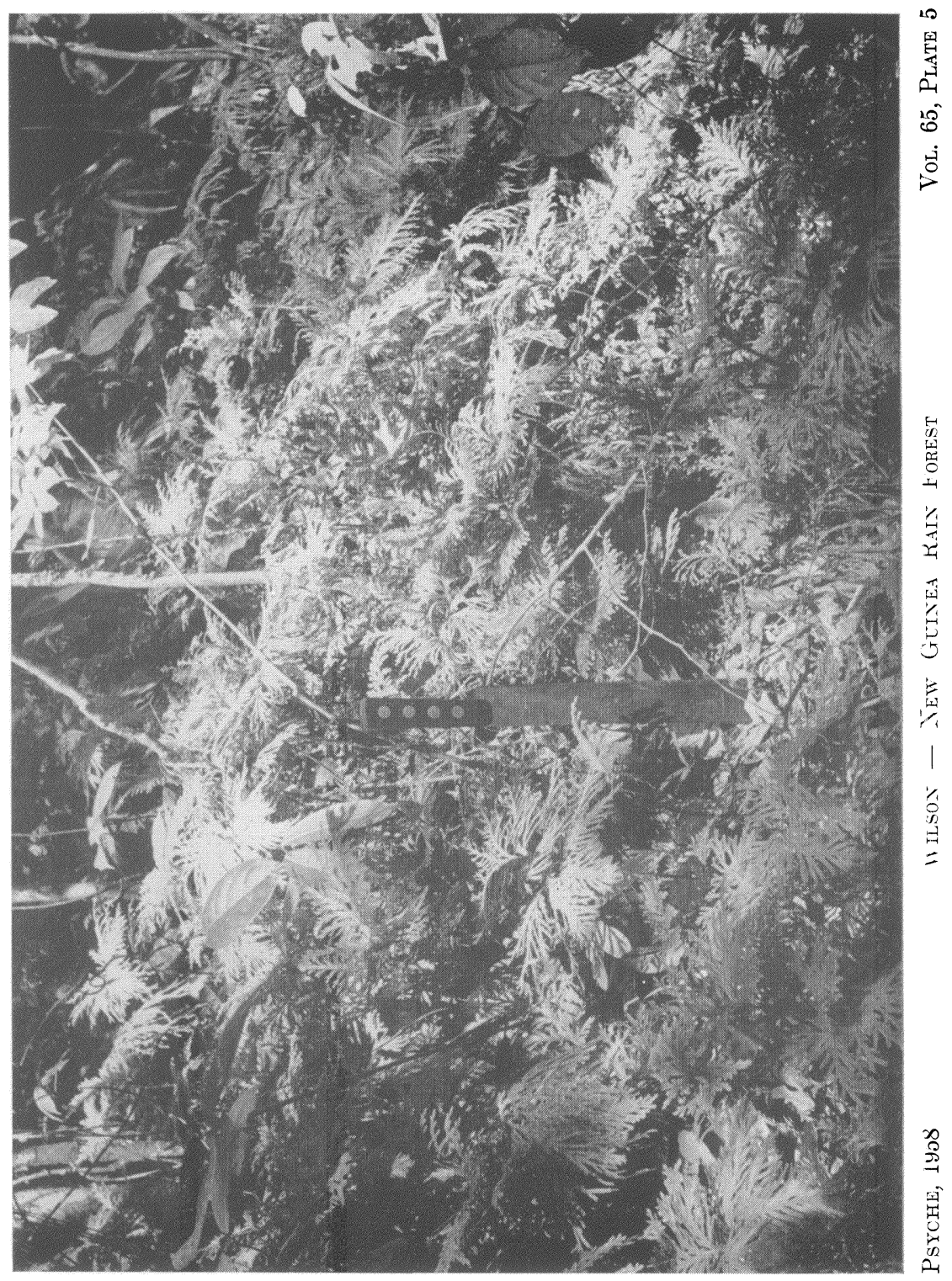


ants, as well as of other kinds of animals, must be considerable. It very possibly hastens the genetic divergence of local populations and plays an important role in the "exuberance" and amplitude that characterizes evolution in the tropics. Probably as the fauna increases in size, in passing from temperate to tropical areas or from small islands to large ones. the diversifying effects of a kaleidoscopic population structure increase exponentially.

There is abundant evidence that similar features of population structure occur in other groups of organisms in tropical forests. Aubrevi'le (1938), in his "mosaic" or "cyclical" theory of regeneration, has described a kaleidoscope pattern in forest trees of the Ivory Coast. Richards (1952) doubts whether the mosaic theory holds for all rain forest associations, but accepts its validity in special cases where certain conditions have been met.

"The poor regeneration of the dominant species in African Forests seems in all probability to indicate that the composition of the community is changing. If the forest is in fact 'untouched and primitive', as Aubreville claims . . . . the changes must be cyclical as the Mosaic theory imp'ies. On the other hand, if the community has undergone disturbance in the past, the present combination of species [in a given sample plot] may be a seral stage and the changes part of a normal (not cyclical) process of development toward a stable climax".

Moreau (1948) finds patchiness a common feature in the distribution of rain forest birds in Tanganyika. Where a species is absent from a locality, it is usually replaced by a related species (from the same family), but not always, leaving some inexplicab'e gaps. The following example is typical:

"Nearly all the montane forests of eastern Africa from Kenya southward are occupied by one or both of the little barbets, Pogoniulus bilineatus and Viridobucco leucomystax. On Hanang Mountain, where both these species are missing, Pogoniulus pusillus, normally a bird of deciduous trees at lower altitudes, appears in the mountain forests 
(Fuggles-Couchman, unpublished). But this does not happen in the neighboring forests of the Mbulu District, where the fruit-eating barbets are not represented at all."

Additional examples from other animal groups and other parts of the tropics (as well as the temperate zones) could be cited to show that patchiness is a widespread phenomenon, on both a very local (microgeographic) and broader (geographic) scale. To all such cases Richards' conditions must be applied, i.e., it must be asked whether patchiness has not arisen exclusively as a result of man-made disturbances. But patchiness as a result of natural disturbances, such as tree falls and stream erosion, is a good possibility also, and should be considered in the future. In the author's present opinion, much of the patchiness observed in New Guinea ant populations has actually arisen through natural disturbances, since enclaves of second-growth vegetation are a normal feature of remote, undisturbed forest. This argument has been taken up in somewhat more detail elsewhere (Wilson, 1959).

\section{SUMMARY}

The population structure of individual Papuan ant species is shown to be generally irregular. Patchiness exists at both a local, clearly ecological level, and a broader, "geographic" level not easily correlated with environmental influences. The combined irregularities in the distributions of multiple species result in distinct shifts of faunal composition and relative abundance over distances of only a few kilometers even in relatively continuous, homogeneous rain forest. The theoretical implications of discordant patchiness with respect to rapid evolution are discussed.

\section{Literature Cited}

Aubreville, A.

1938. La forêt coloniale: les forêts de l'Afrique occidentale française. Ann. Acad. Sci. Colon., Paris, 9: 1-245.

Ford, E. B.

1955. Rapid evolution and the conditions which make it possible. Symp. Quant. Biol. (Cold Spring Harbor), 20: 230-238. 
Kimura, M.

1955. Stochastic processes and distribution of gene frequencies under natural selection. Symp. Quant. Biol. (Cold Spring Harbor), $20 \cdot 33-53$.

Moreau, R. E.

1948. Ecological isolation in a rich tropical avifauna. J. Animal Ecol., 17: 113-126.

RichaRds, P. W.

1952. The tropical rain forest. Cambridge University Press.

Wilson, E O.

1959. Adaptive shift and dispersal in a tropical ant fauna. Evolution (in press). 

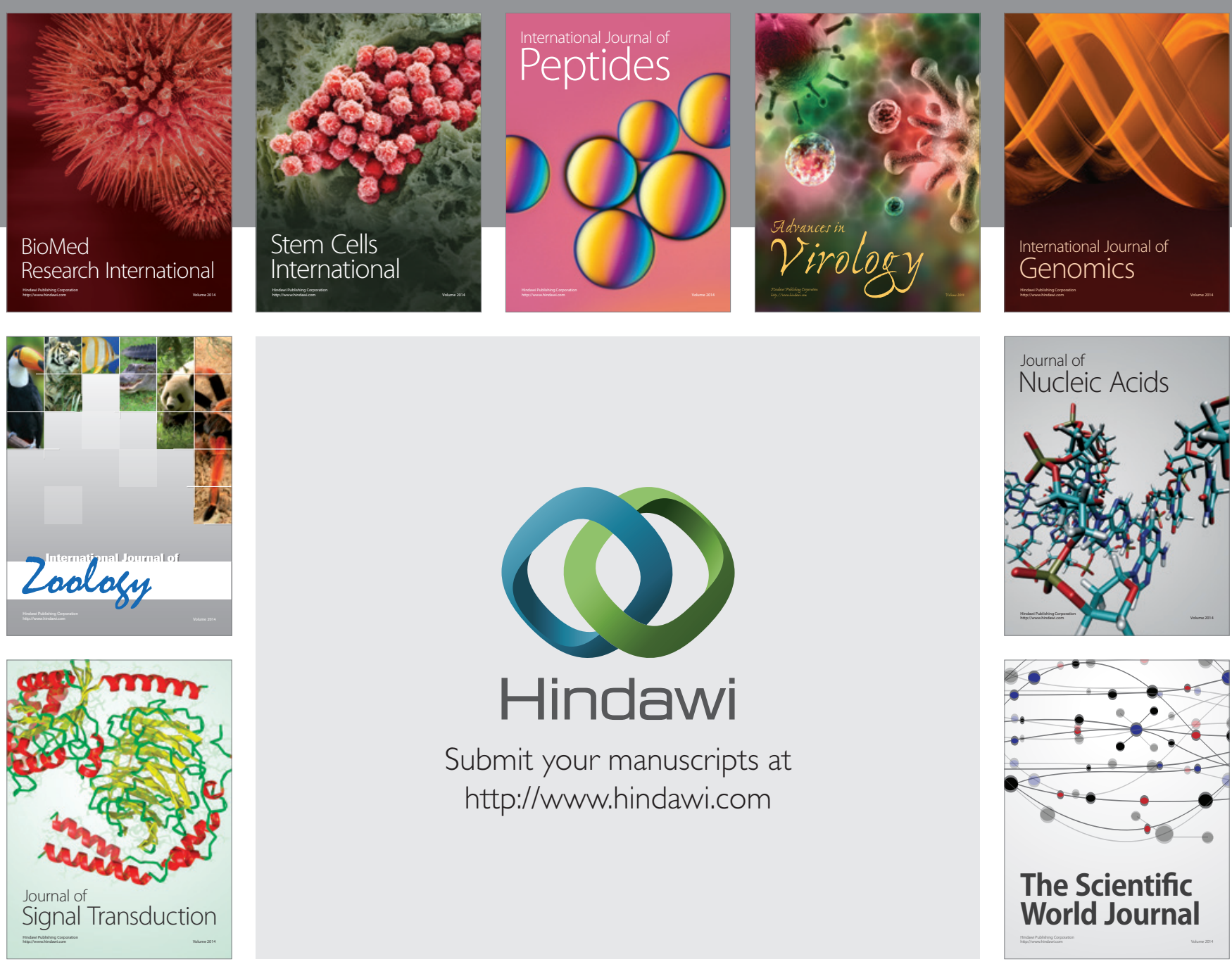

Submit your manuscripts at

http://www.hindawi.com
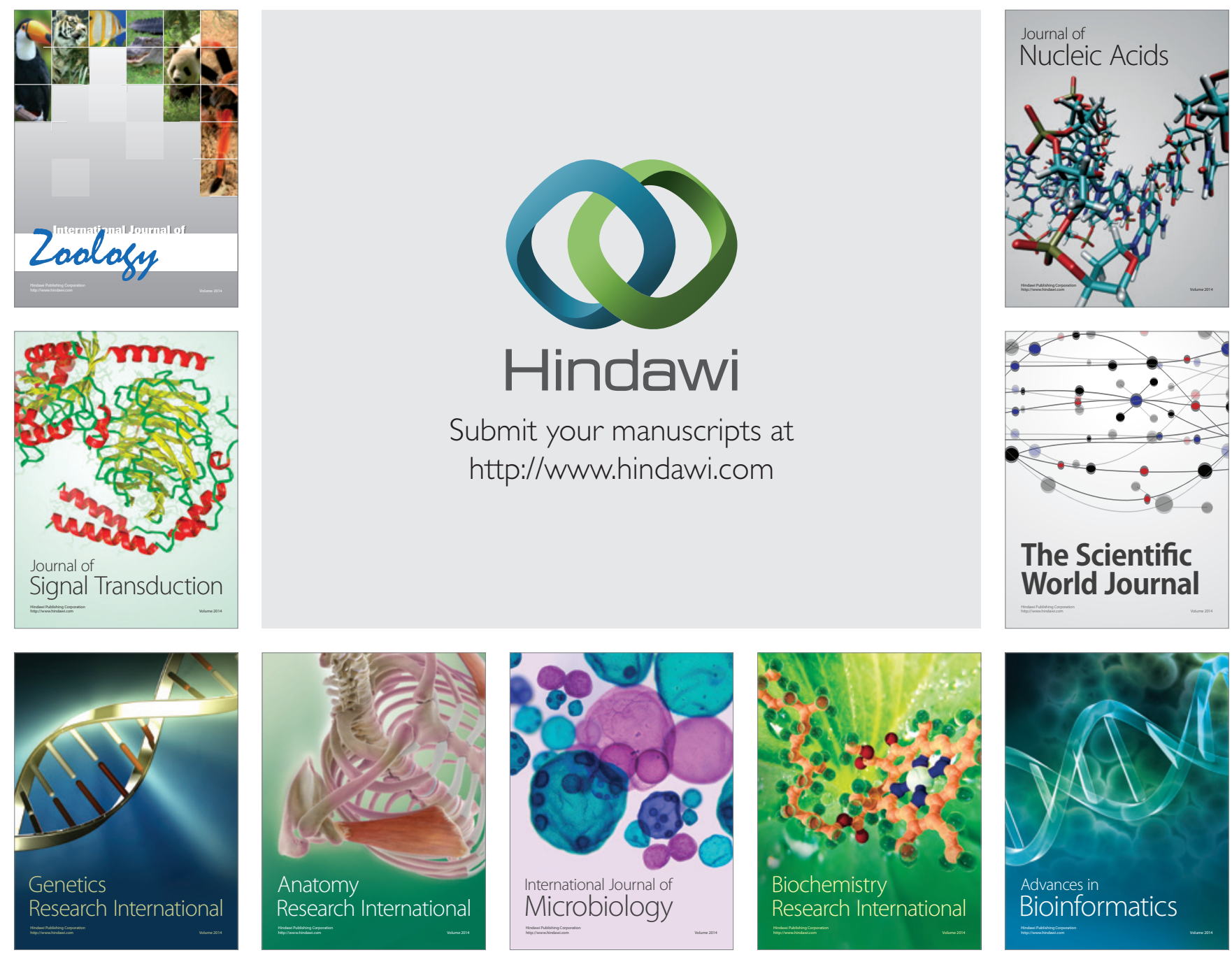

The Scientific World Journal
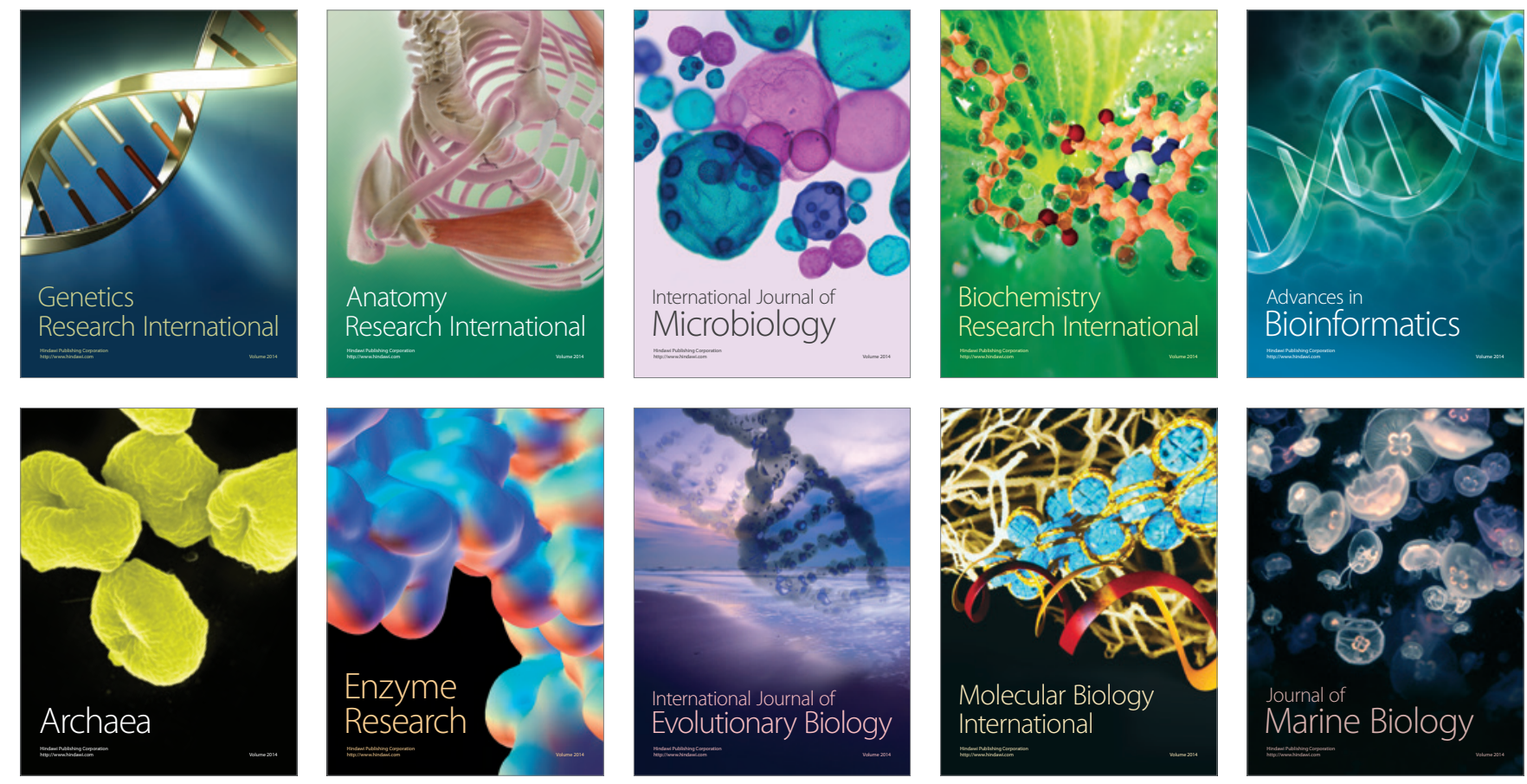